\begin{tabular}{|c|c|c|}
\hline $\begin{array}{l}\text { PKS } \\
\text { PUBLIC } \\
\text { KNOLLEDGE } \\
\text { PROJECT }\end{array}$ & $\begin{array}{l}\text { REVISTA DE GEOGRAFIA } \\
\text { (RECIFE) } \\
\text { http://www.revista.tipe.br/revistageografia }\end{array}$ & $\begin{array}{l}\text { OJS } \\
\frac{\text { OJEN }}{\text { OPUNAL }} \text { JOYNAL } \\
\text { SYSTEMS }\end{array}$ \\
\hline
\end{tabular}

\title{
POTENCIAIS CONFLITOS PELO USO DA ÁGUA NA REGIÃO HIDROGRÁFICA 2 NO ESTADO DE SANTA CATARINA
}

Monica Patrícia Prestes ${ }^{1}$, Manuela Gazzoni dos Passos ${ }^{2}$, Cesar Rodolfo Seibt ${ }^{3}$ Marina Petzen Vieira dos Santos ${ }^{4}$

\footnotetext{
${ }^{1}$ Pós graduanda do MBA em Gestão ambiental, Unoesc Chapecó. . E-mail: monicapprestes@gmail.com

${ }^{2}$ Universidade do Oeste de Santa Catarina. .E-mail: manuela.passos@unoesc.edu.br

${ }^{3}$ Secretaria de Estado de Desenvolvimento Econômico Sustentável de SC.E-mail.cesar.seibt@gmail.com

${ }^{4}$ Bióloga.E-mail: marinapvs@gmail.com
}

Artigo recebido em 25/05/2017 e aceito em 25/08/2018

\begin{abstract}
RESUMO
Os usos múltiplos dos recursos hídricos provocam dentro das bacias hidrográficas disputas pela água tanto em quantidade quanto em qualidade. Buscando fornecer subsídios para auxiliar em uma gestão integrada e compartilhada dos recursos hídricos, o objetivo deste estudo foi identificar os potenciais conflitos pelo uso da água no âmbito da Região hidrográfica do meio oeste do Estado de Santa Catarina (RH2). Foram aplicados 21 questionários aos membros do Comitê de bacias. Os principais conflitos identificados estão relacionados à atividade agroindustrial mostrando-se mais efetivos em períodos críticos de estiagem. Um fator agravante para a resolução dos conflitos é o fato de os instrumentos de gestão ainda não estarem implantados na RH2. As informações obtidas nesta pesquisa servirão de subsídio para a gestão dos recursos hídricos nesta região hidrográfica, buscando solucionar cada conflito de maneira descentralizada e participativa através da aplicação da legislação.
\end{abstract}

Palavras-Chave: Recursos Hídricos, Usos múltiplos da água, Comitê de bacias hidrográficas..

\section{POTENTIAL CONFLICTS FOR THE USE OF WATER IN THE HYDROGRAPHIC REGION 2 IN THE STATE OF SANTA CATARINA}

\begin{abstract}
The multiple uses of water resources cause disputes of water within river basins, for either its amount or its quality. Aiming at providing help to make water resources management integrated and shared this research objective is to identify the potential conflicts regarding water use in the Midwest Hydrographic Region, in the State of Santa Catarina (HR2). To do that 21 questionnaires have been applied to the Basin Committee's members. The main identified conflicts regard the agro-industrial field and they show themselves thornier in critical drought periods. A worsening factor to conflicts solving is the fact the management instruments have not been implemented at the HR2 yet. The information collected in this research shall help manage the water resources in this hydrographic region, seeking to resolve each conflict in a decentralized and participative way by enforcing law.
\end{abstract}

Key Words: Water resources, multiple uses of water, Basin Committee 


\section{INTRODUÇÃO}

A água tem fundamental importância para a manutenção da vida no planeta, e, portanto, falar da relevância dos conhecimentos sobre a água, em suas diversas dimensões, é falar da sobrevivência da espécie humana, da conservação e do equilíbrio da biodiversidade e das relações de dependência entre seres vivos e ambientes naturais (BACCI; PATACA, 2008).

Economias regionais e nacionais dependem da disponibilidade adequada de água para geração de energia, abastecimento público, irrigação e produção de alimentos (agricultura, aqüicultura e pesca, por exemplo) (TUNDISI, 2008). Apesar de existirem alternativas ambientais disponíveis, como o tratamento para os efluentes domésticos e industriais, obras de infraestrutura para melhorar a drenagem urbana, informações computacionais que poderiam armazenar dados de monitoramento e controle, recuperação de áreas degradadas no entorno de rios e nascentes, bem como a possibilidade de planejamento nas bacias hidrográficas, estas dificilmente são executadas devido aos poucos investimentos municipais neste segmento (LEME, 2010).

A população sofre com escassez ou excesso de água em determinados períodos do ano devido à ausência de políticas públicas que incentivem a execução dessas obras e para a implantação dos sistemas de gestão para a cobrança de água, dando valor monetário ao recurso e não apenas aos processos que envolvem a disponibilização de água para o consumo humano (BARROS; AMIN, 2008).

Com o crescimento das áreas urbanas e da população, existe consequentemente o aumento na demanda por água com qualidade para suprir as necessidades básicas. Estima-se que aproximadamente doze milhões de pessoas morrem anualmente por problemas relacionados à qualidade da água (LUNARDI e RABAIOLLI, 2013). Além do consumo humano, é necessário suprir as demandas das indústrias existentes, das novas indústrias, da pecuária e agricultura. Nesse sentido, surgem os conflitos por uso da água principalmente quando estes usos não são planejados.

A Região Hidrográfica do Meio Oeste de Santa Catarina (RH2) abrange 60 municípios com a presença de produção agropecuária, produção hidrelétrica e industrial. A região frequentemente sofre com escassez de água em períodos menos chuvosos, apesar de possuir índices de Precipitação Total Anual (mm), entre 1700 a 2100 mm, considerados um dos maiores do Estado (PANDOLFO et.al., 2002).

Além disso, é notório que a cobertura vegetal de encostas com grande inclinação e topos de morros, bem como a vegetação ripária estão sendo suprimidas, e a qualidade 
da água está diretamente ligada à incidência de vegetação nesses locais (MARQUES, 2010).

Para auxiliar na Gestão dos Recursos Hídricos, torna-se necessário conhecer e identificar os conflitos pelo uso da água existentes na Região Hidrográfica. Essas informações são importantes inclusive para a implantação dos instrumentos de gestão, instituídos pela Política Nacional de Recursos Hídricos.

O objetivo deste estudo foi levantar os potenciais conflitos existentes pelos usos da água na Região Hidrográfica do Meio Oeste do Estado de Santa Catarina (RH2) a partir da percepção dos atores sociais da bacia, membros do comitê de Bacias Chapecó/Irani.

\section{RECURSOS HÍDRICOS E CONFLITOS PELO USO DA ÁGUA}

A água doce é um recurso natural finito e a demanda crescente pelo seu consumo vem despertando a preocupação da sociedade e por isso foi o assunto colocado no centro da questão do desenvolvimento sustentável. Esta preocupação é demonstrada por meio de diversas conferências realizadas nas últimas décadas, pela escolha, por parte da Organização das Nações Unidas, do ano de 2003 como o Ano Internacional da Água Doce e pelo recente estabelecimento, pela mesma entidade, do período 2005 2015, como a Década da Água (ONU, 2005).

O Brasil é um país distinto dos demais com relação aos seus recursos naturais e, entre estes se destacam os recursos hídricos superficiais e subterrâneos. Com aproximadamente 14\% das águas doces do Planeta Terra, o Brasil apresenta, entretanto, sérios problemas de diagnóstico, avaliação estratégica e gestão de seus recursos hídricos (BICUDO et al., 2010).

Apesar da quantidade de água existente no Brasil, existem diversos conflitos pelo uso da água, principalmente devido à concentração de diversos usos. Segundo Gomes e Barbieri (2004) conflitos ocorrem quando o uso dos recursos hídricos adquire um caráter competitivo e, portanto, mutuamente excludente, tais como: entre uso urbano ou rural, abastecimento humano ou industrial, satisfação das necessidades de regiões altamente desenvolvidas ou das necessidades de desenvolvimento de regiões periféricas.

A causa dos conflitos ocorre devido à identificação de conflitos quantitativos em relação à oferta e a demanda não compatível, ou seja, é decorrente da má distribuição 
dos recursos hídricos, tendo como agravante a má gestão deste recurso natural (PEREIRA, 2012).

Devido ao crescimento populacional e ao aumento da demanda de recursos hídricos, a escassez tem se tornado habitual em quase todos os países do mundo (SILVA, 2003). Segundo a Política Nacional de Recursos Hídricos - PNRH (BRASIL, 1997) adotou-se a outorga de direito de uso como um dos instrumentos de regulação para assegurar a quantidade, a qualidade e o regime do recurso. A concessão de outorgas é condicionada à disponibilidade hídrica da bacia, pois fornece o limite máximo permissível para as demandas.

O Brasil se destaca pela grande descarga de água doce, cuja vazão média anual é de $179 \mathrm{mil} \mathrm{m} 3 / \mathrm{s}$, o que corresponde a, aproximadamente, $12 \%$ da disponibilidade hídrica mundial. Porém, devido às dimensões continentais do país, há grandes disparidades regionais em termos de disponibilidade hídrica superficial. A região Amazônica detém, por exemplo, cerca de $70 \%$ dos recursos hídricos superficiais em uma área equivalente a $44 \%$ do território nacional, ocupada por apenas 4,5\% da população brasileira. E esse é um dado comprovado de distribuição desigual dos recursos hídricos, uma grande demanda de água para uma pequena população (MMA, 2006).

Quando há uma indefinição de situações entre indivíduos, acerca de bens, esta resulta em conflitos de interesses, que são os choques de interesses de duas partes em relação a um mesmo bem, com o fim de satisfazer suas necessidades, consequentemente, gerando uma competição que pode vir a se tornar um fator de instabilidade social, de modo que necessitam ser eliminados, para que os mesmos não ponham em risco a existência de toda uma coletividade (OLIVEIRA, 2007).

Os principais causadores de conflitos pelo uso da água no Brasil são a degradação dos mananciais, diminuição de áreas próprias para captação, devido à poluição orgânica e química, contaminação dos rios por esgoto doméstico, industrial e pluvial, falta de drenagem urbana e falta de coleta seletiva, sendo que todas estas condições comprometem o uso da água em termos de qualidade e quantidade (VILAR, 2008). Os conflitos pelo uso de água referem-se a partir de critérios subjetivos ou evidências de escassez de água sendo que um dos motivos para que ocorra um conflito de uso de água pode ser a inexistência de informações que associem a disponibilidade hídrica com as vazões já outorgadas, e esta inexistência está diretamente ligada na falta de planejamento e gerenciamento de recursos hídricos (MOREIRA et. al., 2012). 
Os conflitos existentes entre atores sociais do poder público em relação à gestão das águas têm decorrência da dificuldade de conciliação das funções institucionais. Existe uma grande carência de dados hidroambientais, o que dificulta a criação de política de fiscalizações ambientais (MAGALHÃES JÚNIOR, 2007).

A Política Nacional de Recursos Hídricos cria o Sistema Nacional de Gerenciamento de Recursos Hídricos (Lei 9.433/1997) (BRASIL, 1997) e os Comitês e Agências de Bacias são inseridos justamente para intermediar esses conflitos dos múltiplos usos da água e para implementar a política nacional de recursos hídricos em bacias brasileiras. Mas para os comitês e Agências de bacias alcançarem este objetivo é necessária a implementação dos Instrumentos da política.

Um dos instrumentos é a outorga de direito de uso tendo por objetivo racionalizar e disciplinar o uso, evitando ou equacionando situações de conflito. Dessa maneira, é possível o controle dos volumes captados em uma determinada bacia hidrográfica, do período em que as captações ocorrem e sua finalidade, contemplando os usos prioritários e as determinações dos planos de recursos hídricos e dos comitês de bacia hidrográfica (CRUZ, 2001).

Os instrumentos de gestão possuem objetivos de aplicação distintos e devem ser utilizados para alcançar diferentes fins. Por exemplo, há instrumentos de disciplinamento (outorga), há instrumentos de incentivo (cobrança) e há instrumentos de apoio (sistemas de informação) (PORTO e PORTO, 2008). Esses com suas respectivas facilidades/dificuldades e vantagens/desvantagens, não são excludentes entre si, embora não seja trivial sua implantação conjunta e de modo articulado, a maior eficácia certamente virá da aplicação conjunta dos diversos instrumentos, utilizando-os de acordo com sua potencialidade para melhor resolver o problema em questão (PORTO e LOBATO, 2004).

Segundo Oliveira e Fioreze (2011), a disponibilidade hídrica necessita de monitoramento contínuo e realização de estudos que contabilizam a situação atual e estimam como será futuramente. Para que a implantação do instrumento da outorga possa ser realizada de maneira mais efetiva, é necessário o conhecimento do comportamento nas bacias hidrográficas, especialmente a determinação das vazões de referência, a fim de fundamentar o processo decisório. Decisões tomadas a partir de informações de vazão pouco representativas podem comprometer a gestão e o planejamento de recursos hídricos. 
Quanto ao Oeste do Estado de Santa Catarina, segundo o Plano Estratégico de Gestão integrada da Bacia hidrográfica do Rio Chapecó (2009), a situação dos corpos hídricos em função da qualidade da água apresenta-se, na sua grande maioria como "rios com grave poluição aparente", sendo a situação considerada "extremante crítica". Além disso, apresenta percentuais relativos à predominância de problemas na área ambiental dentro da bacia do Rio Chapecó, sendo que: $85 \%$ de todas as microbacias apresentam problemas relacionados à quantidade e qualidade da água; $87 \%$ por degradação do solo; $91 \%$ por poluição (homem/água/solo); $62 \%$ falta de saneamento básico; 35\% pela grande existência de insetos/animais/esterqueiras; 38\% inexistência de Educação ambiental e 19\% os problemas estão relacionados à legislação e falta de fiscalização. Já os problemas relacionados á área social que ocorrem em todas as micro bacias do Oeste de SC são: conservação das construções (68\%), áreas de lazer (44\%), participação social/valorização social (90\%), infra-estrutura (73\%), educação (24\%), saúde $(41 \%)$ e políticas adequadas (20\%) (Plano Estratégico da Bacia Hidrográfica do Rio Chapecó, 2009).

\section{PROCEDIMENTOS METODOLÓGICOS}

Esta pesquisa foi realizada na Região hidrográfica 2 do Estado de Santa Catarina, localizada no meio-oeste catarinense (Figura 1) com uma área de aproximadamente $11.122 \mathrm{~km}^{2}$, abrangência de 60 municípios e uma população de 600.745 habitantes (IBGE, 2010). O Comitê de bacias hidrográficas atuante na RH2 é o Comitê de Bacias hidrográficas Chapecó/Irani e contíguos, contando com 65 entidades membros.

Para a realização deste trabalho foram aplicados questionários e entrevistas semi estruturadas a 21 membros das entidades participantes do Comitê de Bacias Hidrográficas Chapecó/Irani. O questionário foi elaborado com oito perguntas abertas e cinco perguntas fechadas, considerando o que cada entidade entende por conflito e o período de tempo em que eles ocorrem. Foram questionados também sobre a região hidrográfica, os principais usos, as principais disputas entre dois usos diferentes pela mesma demanda de água. Além de questionado sobre as metodologias visualizadas para resolução destes conflitos.

Estas entidades foram selecionadas através de análise levando em consideração: a) Área de abrangência da Entidade; b) Atividades ligadas diretamente ao uso de recursos hídricos; c) Participação no Comitê de Bacias; d) Conhecimento do entrevistado em relação à Bacia Hidrográfica; e) Histórico de dados da Entidade. 
Figura1. Municípios inseridos na Região Hidrográfica 2 do estado de SC.

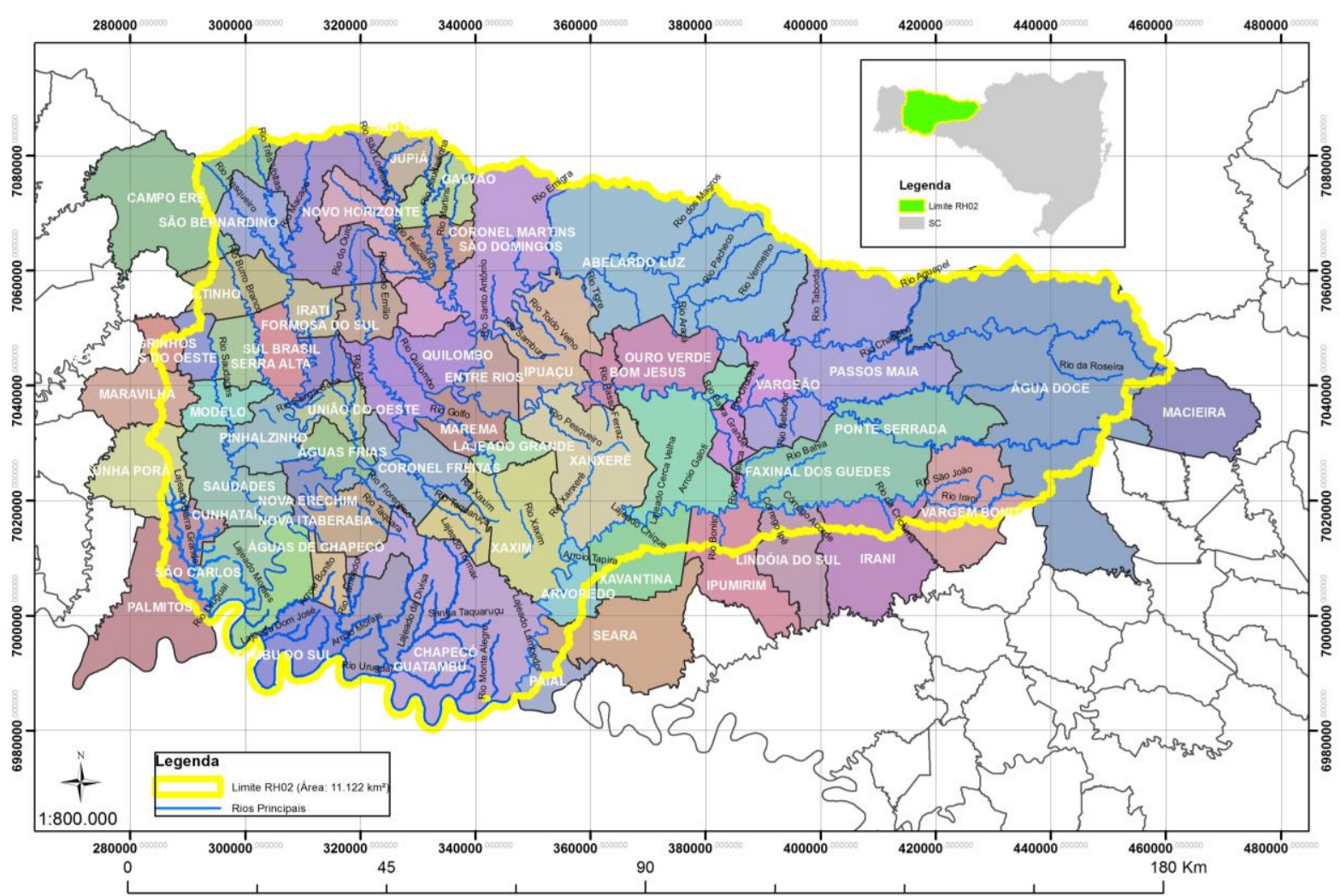

Fonte: Adaptado de AGUAS, 2015.

Após o levantamento das informações, os dados foram tabulados de acordo com a semelhança das respostas.

Para confirmação dos resultados foi realizada entrevista semi estruturada com os participantes para esclarecer sobre o conflito apontado, a fim de identificar a localização precisa de onde o conflito citado se encontrava.

Os dados obtidos com a pesquisa foram apresentados em Assembleia Geral Ordinária do Comitê Chapecó/Irani em dezembro de 2016, onde os membros puderam discutir e levantar novos conflitos que não haviam sido pontuados pelos entrevistados.

As questões abordadas foram: a) O que você entende por conflito de uso de água? b) Qual o período (tempo) que estes potenciais conflitos podem ocorrer? C) Você conhece algum conflito permanente pelo uso de água em sua região? Se sim, quais são? Descreva-os. d)Você observa alguma metodologia de resolução para estes potenciais conflitos? Como você pode contribuir? e) Cite quais disputas/conflitos ocorrem na sua região? f) Em que locais encontram-se os conflitos apontados acima? Descreva-os com 
pontos de referência ou coordenadas geográficas. g)Em período de estiagens existe a falta de água para abastecimento da população e os animais, assim como para a agricultura, pecuária e indústrias em sua região? h) Na sua concepção, qual o nível de importância em fazer gestão dos recursos hídricos na Bacia do Rio Chapecó e Irani?

\section{RESULTADOS E DISCUSSÕES}

Dos 21 questionários aplicados em toda a $\mathrm{RH} 2,43 \%$ foram para entidades representantes dos usuários de água, 28,5\% representantes da Sociedade civil e 28,5\% entidades que compõem o Poder Público Federal, Estadual e Municipal.

O primeiro questionamento acerca do entendimento sobre a ocorrência dos conflitos na região onde se localiza, $30 \%$ dos entrevistados citaram que os conflitos ocorrem tanto por quantidade quando qualidade, $25 \%$ relacionaram os conflitos apenas a quantidade por não atender a demanda dos usos, $20 \%$ demonstraram reconhecer a ocorrência dos conflitos, mas, não identificaram as causas (Gráfico 1). Os outros 25\% responderam de forma ampla ou não atenderam ao objetivo da pergunta. Quando questionados sobre o período que os conflitos, a maioria $(65 \%)$ citou que os conflitos ocorrem na época de estiagem.

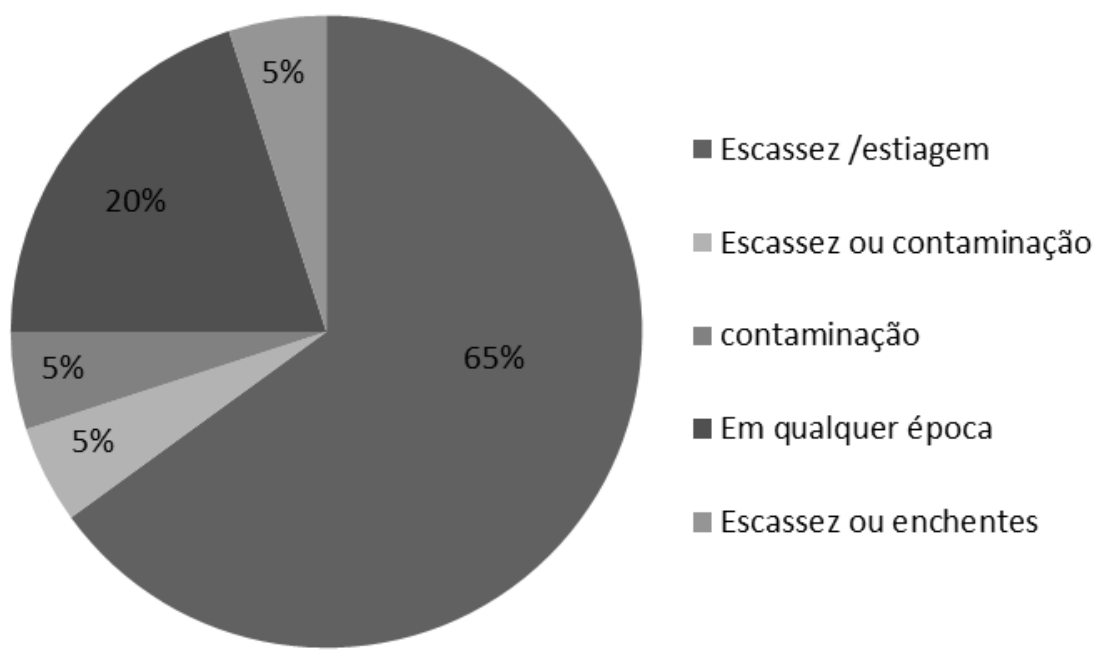

Gráfico 1. Cenário em que ocorrem conflitos pelo uso da água na RH2 do Estado de SC.

Ao serem questionados sobre a existência de conflitos permanentes na RH2, 52,4\% disseram que existem conflitos permanentes e $47,6 \%$ relataram que os conflitos de seu conhecimento não podem ser classificados como permanentes, pois, ocorrem em determinado período e dependem das condições climáticas. 
Os conflitos são decorrentes de usos competitivos em relação a uma quantidade insuficiente de água para atender às necessidades dos diversos usos de água em uma bacia hidrográfica. Esses conflitos podem ser permanentes ou temporários, uma vez que estão relacionados às variações do ciclo hidrológico ou, também, da presença de vários usuários (COPPE/UFRJ, 2001).

Fica evidente segundo os entrevistados que os conflitos ocorrem em épocas pouco chuvosas, ou seja, de maior estiagem. Durante o restante do ano, em função da maior disponibilidade de água, estes conflitos são esquecidos pela população. Destacase a dificuldade na resolução destes conflitos, visto que são temporários. Outro fato que contribui para que os conflitos não sejam resolvidos é a ausência dos instrumentos de gestão na bacia hidrográfica. Levando-se em conta os instrumentos de gestão, esta bacia possui apenas o Plano de bacia do rio Chapecó.

Em comunicação pessoal, o presidente do Comitê Chapecó/Irani aponta que o Plano de bacia do Rio Chapecó é muito amplo e de caráter sugestivo/propositivo, não possui dados primários e não apresenta metodologias para a implantação dos instrumentos de gestão. Além disso, os Comitês também não possuem estrutura técnica para execução do Plano. No caso da $\mathrm{RH} 2$ o fato de apenas um dos rios principais possuir plano (o Rio Chapecó) torna ainda mais complicado o levantamento de dados. Para o Rio Irani, ainda não há previsão para início da elaboração de seu plano, enquanto o Plano do Rio Chapecó já precisa de revisão.

Essa falta de informação também dificulta uma coerente gestão da bacia hidrográfica. A ausência do Instrumento da PNRH - Sistema de informações faz com que informações que existem na bacia através por exemplo, de Usinas hidrelétricas, não cheguem ao Comitê de Bacias. A ausência de recursos financeiros e humanos também impede a produção de dados primários de pesquisa que possam contribuir. Candeias et al (2014) propuzeram a construção de um Atlas Eletrônico Analítico que permite ao usuário consultar e gerar mapas interativamente, como mapas temáticos. Essa possibilidade permite informações que servem de subsídio na tomada de decisões.

O número de cadastros de usuários realizados é baixo para o tamanho da bacia. Na Bacia Hidrográfica do Rio Chapecó foram computados 11.349 cadastros e na Bacia do Rio Irani, 2.178 cadastros (SDS, 2016). Segundo Magalhães Júnior (2007), apesar da decisão em grupo ser um processo mais lento que indivíduos isolados para a tomada de decisões, a discussão em grupo aumenta as chances de melhor escolha pra resolução de problemas. Por este motivo, vê-se a necessidade de envolver o grupo dos três 
segmentos que compõem o Comitê (Poder Público, Sociedade Civil e Usuários de Água).

Foram identificados 27 conflitos, listados conforme Tabela 1. No momento em que os conflitos levantados foram apresentados aos membros do comitê, foi possível observar que há dificuldade na clareza do que é um conflito. Esta informação pode ser utilizada para subsidiar ações de capacitação aos membros do comitê.

Nas discussões realizadas durante a Assembleia Geral ordinária, percebeu-se a fala dos membros no sentido de que a gestão dos recursos hídricos só funcionará efetivamente quando for instituído um dos instrumentos de gestão que é a cobrança. A Resolução do Conselho Nacional de Recursos Hídricos $n^{\circ} 48$ estabelece os critérios gerais para a cobrança. A cobrança objetiva principalmente: reconhecer a água como um bem público limitado dotado de valor econômico, incentivar a racionalização do uso da água, obter recursos financeiros para o desenvolvimento de projeto, estimular o incentivo a despoluição, induzir e estimular a conservação dos recursos hídricos (GOVERNO DE SANTA CATARINA, 2013). 
Tabela 1. Conflitos levantados na RH2 do Estado de SC.

\begin{tabular}{|c|c|c|}
\hline $\begin{array}{c}\text { Número do } \\
\text { conflito }\end{array}$ & Conflito & $\begin{array}{l}\text { Repetições } \\
\text { de respostas }\end{array}$ \\
\hline 1 & Guatambu - Lajeado Tigre: Indústria $\mathrm{x}$ abastecimento público $\mathrm{x}$ hidrelétrica & 5 \\
\hline 2 & Chapecó - Lajeado São José: Abastecimento público x Indústria & 5 \\
\hline 3 & Xavantina - Rio Irani: Hidrelétrica x agropecuária & 1 \\
\hline 4 & Cunhataí - Distrito de Barra Grande: Abastecimento público x Agropecuária & 1 \\
\hline 5 & Passos Maia: Lazer x Agropecuária & 1 \\
\hline 6 & Xaxim -Interior: Abastecimento público x Dessedentação animal & 1 \\
\hline 7 & Xaxim: Indústria x pessoa física (captação de água de poço artesiano) & 1 \\
\hline 8 & Águas Frias (Salto da Meia Lua) -Lazer x Agropecuária & 2 \\
\hline 9 & Águas de Chapecó: Barragem Foz: Hidrelétrica x Lazer & 2 \\
\hline 10 & Sul Brasil - Rio Burro Branco: Hidrelétrica. x Abast. Público x Esgotamento Sanitário x Agropecuária & 2 \\
\hline 11 & Caxambu do Sul - Rio Uruguai: Hidrelétricas x Abastecimento Público & 1 \\
\hline 12 & Xanxerê: Rio Ditinho: Abastecimento público x Agropecuária & 1 \\
\hline 13 & Barragem foz: Hidrelétrica x agropecuária & 1 \\
\hline 14 & Chapecó: Esgotamento Sanitário x Indústria & 1 \\
\hline 15 & Chapecó - Goio-en, Rio Uruguai: Lazer x Hidrelétrica x Agropecuária & 2 \\
\hline
\end{tabular}




\begin{tabular}{lll}
\hline 16 & Palmitos - Rio Uruguai: Abastecimento público x hidrelétrica & 1 \\
17 & Saudades: Lazer x Agropecuária & 1 \\
18 & Concórdia: Lazer x Agropecuária & 1 \\
19 & São Domingos (Prainha): Lazer x Hidrelétrica & 1 \\
20 & Abelardo Luz (Prainha): Lazer x Agropecuária & 1 \\
21 & Chapecó: Esgotamento Sanitário x Expansão urbana & 1 \\
22 & Chapecó - Lajeado Carneiro: Indústria x outros usos \\
23 & Pinhalzinho - Rio Saudade: Indústria x Laticínio & 1 \\
24 & Em vários municípios da RH2: Abastecimento público x agropecuária & 3 \\
25 & Guatambu - Lazer x Esgotamento Sanitário & 1 \\
26 & Guatambu - Esgotamento Sanitário x Piscicultura & 1 \\
27 & Cordilheira Alta (Nascentes) - Expansão Urbana x Agropecuária & 1 \\
\hline
\end{tabular}


A partir dos conflitos citados eles foram classificados de acordo com categorias, conforme quadro 2. Foram identificadas 17 categorias.

Tabela 2. Categorias de conflitos levantados na RH2.

\begin{tabular}{lc}
\hline \multicolumn{1}{c}{ Categorias de conflitos } & $\begin{array}{c}\text { Número de } \\
\text { respostas }\end{array}$ \\
\hline Indústria x abastecimento público & 3 \\
Esgotamento sanitário x abastecimento público & 1 \\
Hidrelétricas x abastecimento público & 4 \\
Hidrelétricas x indústria & 1 \\
Esgotamento sanitário x indústria & 1 \\
Irrigação x abastecimento público & 0 \\
Irrigação x indústria & 0 \\
Lazer x abastecimento público & 0 \\
Lazer x esgotamento sanitário & 1 \\
Lazer x indústria & 0 \\
Agropecuária x Indústria & 1 \\
Agropecuária x Hidrelétrica & 3 \\
Agropecuária x Abastecimento público & 3 \\
Hidrelétrica x Lazer & 3 \\
Agropecuária x Lazer & 6 \\
Não há conflito & 1 \\
Outros & 5 \\
\hline Fonte: & 3 \\
\hline
\end{tabular}

Fonte: o autor, 2016.

Quanto aos usos mais afetados em épocas de estiagem, foi possível perceber que $42 \%$ dos entrevistados citaram a atividade Agropecuária (gráfico 2).

Os conflitos mais citados envolvem a atividade Agroindustrial, devido à grande demanda de água necessária para a produção e processamento de alimentos. Com relaçao às disputas de água que mais frequentemente podem ocorrer, a mais citada foi entre abastecimento público e agropecuária. Neste contexto, visualiza-se a disputa dos dois usos prioritários o consumo humano e a dessedentação animal. A agropecuária foi a atividade avaliada como a que mais sofre com a falta de água em épocas de estiagem. Isso se deve ao 
fato do meio oeste de SC ser um grande produtor de aves, bovinos e suínos. Outra disputada mencionada foi entre abastecimento público e esgotamento sanitário.

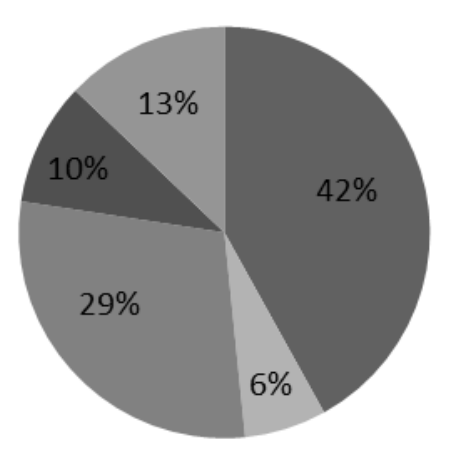

\author{
- Agropecuária \\ Em todos os segmentos \\ - Abastecimento público \\ - industria \\ - Não identificou atividade
}

Gráfico 2: Atividade mais prejudicada pela estiagem na RH2.

Avaliando a área de abrangência da RH2, pode-se considerar que o número de conflitos citados não tenha contemplado todos os municípios. Por outro lado, $74 \%$ dos municípios são de pequeno porte, com menos de 10 mil habitantes, e não possuem atividades que utilizam grandes demandas de água (PASSOS, et. al., 2015).

Em relação à classificação da importância da gestão dos recursos hídricos na RH2, nenhum entrevistado se mostrou indiferente e apenas um disse ser pouco importante os demais consideraram a gestão dos recursos hídricos muito importante.

Quando questionado sobre as metodologias possíveis para a resolução destes conflitos citados, destacam-se: a participação no Comitê de Bacias Hidrográficas, a implementação de instrumentos de gestão, a gestão dos recursos hídricos e a participação das entidades em diversos projetos ambientais.

\title{
CONSIDERAÇÕES FINAIS
}

Através da realização deste estudo observou-se que em sua maioria os conflitos acontecem devido à falta de água, ocorrendo mais frequentemente em épocas de estiagem além de serem pontuais. Percebe-se que a maioria dos membros não tem conhecimento claro em relação ao que realmente é um conflito pelo uso de água, relacionando muitas vezes o conflito com a baixa qualidade de água do local. 
Além disso, a gestão dos conflitos é um dos emblemas na Gestão dos Recursos Hídricos. Precisa-se avaliar individualmente cada um dos conflitos levantados e levar ao Comitê de Bacias Hidrográficas as discussões para selar acordos entre os usos e garantindo a prioridade destes. Destaca-se também a necessidade da instituição dos Instrumentos da política nacional de recursos hídricos para mediar os conflitos desta bacia.

\section{AGRADECIMENTOS}

Ao Governo do Estado de Santa Catarina pela concessão de bolsa através do Fundo de Apoio à Manutenção e ao Desenvolvimento da Educação Superior - FUMDES.

\section{REFERÊNCIAS}

AGUAS. Maspas dos rios Chapecó e Irani. Disponível em: http://www.aguas.sc.gov.br/base-documental-rio-chapeco-irani/mapas-rio-chapecoirani. Acesso em: 05/08/2015

BACCI, D. C.; PATACA, E. M. Educação para a água. Estudos avançados. v. 22, n. 63, p. $211-226,2008$.

BARROS, F. G. N.; AMIN, M. M. Água: um bem econômico de valor para o Brasil e o mundo. Revista Brasileira de Gestão e Desenvolvimento Regional, Taubaté, v. 4, n. 1, p.75-108, abr. 2008.

BICUDO, C.E.de M.; TUNDISI, J.G.; SCHEUENSTUHL, M.C.B. ,orgs. Águas do Brasil: análises estratégicas. São Paulo, Instituto de Botânica, 2010. 224 p.

CANDEIAS, Ana Lúcia Bezerra et al. Atlas Eletrônico Analítico como Ferramenta na Gestão dos Recursos Hídricos. Revista de Geografia (Recife), v. 30, n. 3, p. 226-243, 2014.

COPPE/UFRJ, Laboratório de Hidrologia e Estudos do Meio Ambiente da. Plano de Recursos Hídricos para a Fase Inicial da Cobrança na Bacia do Rio Paraíba do Sul. Rio de Janeiro: Ceivap, 2001. 8 v. Disponível em: <http://www.hidro.ufrj.br/pgrh/pgrh-re-010r0/volume3/pgrh-re-010-r0-vol3-cap4.pdf>. Acesso em: 11 dez. 2016.

GOMES, Jésus de Lisboa; BARBIERI, José Carlos. Gerenciamento de recursos hídricos no Brasil e no Estado de São Paulo: um novo modelo de política pública. Cad. EBAPE.BR, Rio de Janeiro, v. 2, n. 3, p. 01-21, Dec. 2004

GOVERNO DE SANTA CATARINA. Coletânea de Legislação de Recursos Hídricos do Estado de Santa Catarina. Florianópolis: Dioesc, 2013. 445 p. 
LEME, T. N. Os municípios e a política nacional do meio ambiente. Planejamento e Políticas

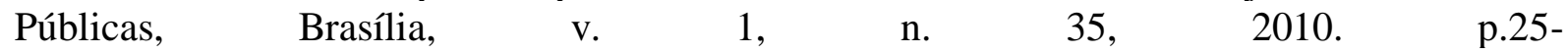
52.<http://ipea.gov.br/ppp/index.php/PPP/article/viewFile/196/191>. Acesso em: 18 nov. 2016.

LUNARDI, J.; RABAIOLLI, J. A.. VALORIZAÇÃO E PRESERVAÇÃO DOS RECURSOS HIDRÍCOS NA BUSCA PELO DESENVOLVIMENTO RURAL SUSTENTÁVEL. Revista Okara: Geografia em Debate, João Pessoa, v. 7, n. 1, p.44-62, dez. 2013.

MAGALHÃES JÚNIOR, A. P. Indicadores ambientais e recursos hídricos: realidade e perspectivas para o Brasil a partir da experiência Francesa. -Rio de Janeiro: Bertrand Brasil, 2007.

MARQUES, R. Variabilidade Da Precipitação Na Bacia Hidrográfica Do Rio Tubarão/Sc De 1946 A 2006. 2010. 206 f. Dissertação (Mestrado) - Curso de Geografia, Departamento de Geociências, Universidade Federal de Santa Catarina, Florianópolis, 2010. Disponível em: <file:///C:/Users/Usuario/Downloads/Variabilidade-da-precipitação-na-baciahidrográfica-do-Rio-Tubarão-SC-de-1946-a-2006 (1).pdf>. Acesso em: 14 abr. 2015.

MOREIRA, M. C. SILVA, Demetrius David da. PRUSKI, Fernando Falco. LARA, Marcelo dos Santos. Índices para Identificação de Conflitos pelo Uso da Água: Proposição Metodológica e Estudo de Caso. Artigo. Revista Brasileira de Recursos Hídricos. v.7.n.3.Jul/set,2012. Porto Alegre: RBRH, 2012.

OLIVEIRA, Luiz F. C de; FIOREZE, Ana P. Estimativas de vazões mínimas mediante dados pluviométricos na Bacia Hidrográfica do Ribeirão Santa Bárbara, Goiás. Revista Brasileira de Engenharia Agrícola e Ambiental. v.15, n.1, p.9-15, 2011.Campina Grande. Disponível em: http://www.agriambi.com.br. Acesso: 12 de mio de 2017.

OLIVEIRA, T. P. Análise jurídica dos conflitos de uso da água na realidade brasileira: o caso da bacia hidrográfica do rio São Francisco, 2007. Disponível em: <file:///C:/Users/Maiara/Downloads/conflitos de usos (1).pdf>. Acesso em: 04 fev. 2015.

PANDOLFO, C; BRAGA, H. J; SILVA JUNIOR, V. P; MASSIGNAN, A. M;PEREIRA, E. S; THOMÉ, V. M. R; VALCI, F. V. Atlas Climatológico do Estado de Santa Catarina. Florianópolis: Epagri, 2002.

PEREIRA, E. M. Análise De Conflitos Pelo Uso Da Água Relacionados À Oferta E À Demanda: Bacia Do Rio Piracicaba - MG. Belo Horizonte: UFMG, 2012.

PORTO, M. F. A.; LOBATO, F. Mechanisms of Water Management: Command \& Control and social Mechanisms. Revista de Gestion Del'agua de America Latina, v.2, p.113-29, 2004.

PORTO, M. F. A; PORTO, R. L. L. Gestão de bacias hidrográficas. Estudos avançados. v. 22, n. 63 , p. $43-60,2008$. 
SILVA, A. M. Gestão de conflitos pelo uso da água em bacias hidrográficas urbanas. 2003. 151 f. Dissertação (Mestrado) - Curso de Programa de Pós-graduação em Engenharia Civil, Centro Tecnológico, Universidade Federal do Pará, Belém, 2003.

TUNDISI, J. G. Recursos hídricos no futuro: problemas e soluções. Estudos avançados. v. 22, n. 63 , p. $1-10,2008$.

VIEIRA, Z. M. C. L. Metodologia de Análise de Conflitos na Implantação de Medidas de Gestão de Demanda de Água. Tese de Doutorado. Universidade Federal de Campina Grande. UFCG. 2008. Campina Grande, 2008. 